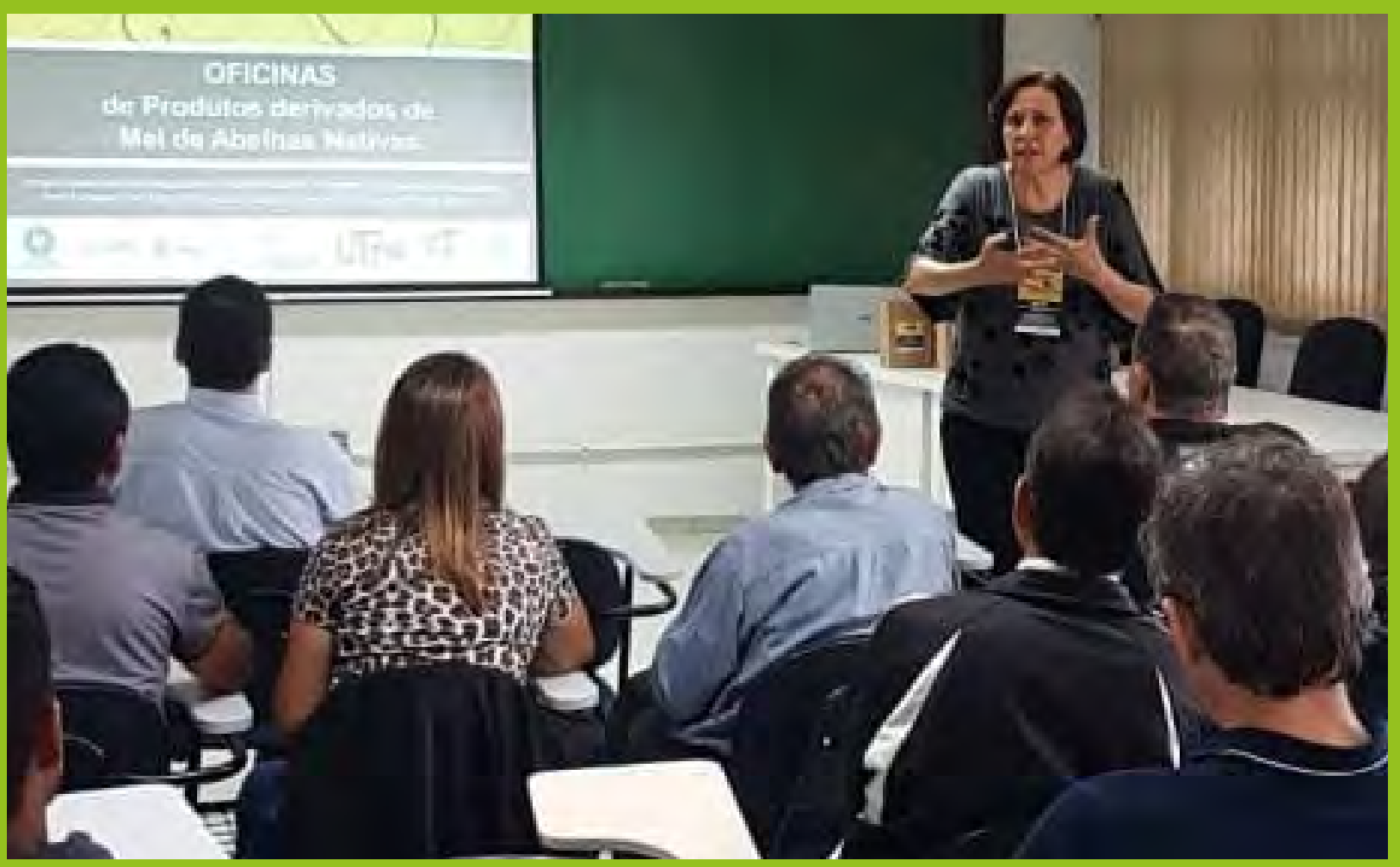

\title{
Extensão inovadora para agregação de renda à cadeia produtiva de mel de abelhas-sem-ferrão
}

Wilma Aparecida Spinosa - wilma.spinosa@uel.br ${ }^{1}$

Fernanda Carla Henrique Bana - ferhenriquebana@gmail.com 2

José Humberto Soares - jhsoares@idr.pr.gov.br 3

Ana Claudia Arruda Motta Alves - anaclaudiamotta99@gmail.com ${ }^{4}$

\section{RESUMO}

A meliponicultura ou criação de abelhas-sem-ferrão possibilita aos agricultores familiares a extração e a comercialização de mel como fonte de alimentação e renda. Este artigo tem como objetivo relatar o desenvolvimento de uma barra de cereais com mel de abelha-sem-ferrão, de fácil execução, e a transferência desse produto inovador aos meliponicultores da região de Londrina-PR. Um convênio entre instituições oportunizou a oferta de um curso teórico e de uma oficina de elaboração de barra de cereais aos produtores de mel. Como resultado, os professores e alunos se sentiram valorizados por atenderem demandas reais da comunidade externa, ampliando seus conhecimentos técnicos e sua interação social. Os meliponicultores, por sua vez, conheceram uma nova forma de diversificação de produtos e geração de renda.

\footnotetext{
1 Doutora em Ciência de Alimentos pela Universidade Estadual de Campinas (UNICAMP). Professora Adjunta da Universidade Estadual de Londrina (UEL).

2 Doutora em Ciência de Alimentos pela Universidade Estadual de Londrina (UEL). Estagiária de Pós-Doutorado do Programa de Pós-Graduação em Ciência de Alimentos da UEL.

3 Mestre em Ciência de Alimentos pela Universidade Estadual de Londrina (UEL). Extensionista rural do Instituto de Desenvolvimento Rural do Paraná (IDR-IAPAR-EMATER).

4 Graduanda em Química na Universidade Estadual de Londrina (UEL).
} 


\title{
Innovating university extension for adding income to the stingless bees honey production chain
}

\begin{abstract}
Meliponiculture or stingless bee culture allows family farmers to extract and commercialize honey as a source of food and income. This article aims to report the development of a stingless bee honey cereal bar, which is easy to be produced, and the transfer of this innovative product to the meliponists in the region of Londrina-PR. An agreement between institutions made it possible to offer a theoretical course and a workshop for the preparation of cereal bars to honey farmers. As a result, teachers and students felt valued for meeting real demands from the external community, expanding their technical knowledge and social interaction. Meliponists, in turn, experienced a new form of product diversification and income generation.
\end{abstract}

KEYWORDS: cereal bar; meliponiculture; innovative product; training; social inclusion.

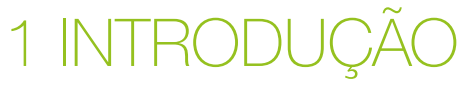

É de considerável importância o papel da agricultura familiar nos países em desenvolvimento, como o Brasil, onde considerável parte da renda de pessoas que vivem na zona rural advém de atividades realizadas em suas próprias comunidades. Nesse contexto, é necessário que a sociedade civil, as parcerias de fomento à agricultura familiar, as universidades e outros setores da sociedade deem sua contribuição, seja de ordem técnica, logística ou financeira, para a mitigação da desigualdade social (LIMA, SILVA e IWATA, 2019). Diversos grupos, localizados em diferentes universidades do país, têm concretizado trabalhos de extensão na busca de ampliar a geração de emprego e renda e também aumentar a autoestima e a qualidade de vida dos participantes (CARRETA e LOBATO, 2010; MELO, 2015; ANDRADE et al., 2016).

A exploração de culturas que possibilitem a complementação de renda das comunidades rurais é um caminho para maior inclusão social. Como exemplo, pode-se elencar a utilização da meliponicultura, que é a criação e manejo das abelhas indígenas (nativas) sem ferrão ou meliponíneos. Esta atividade propicia às comunidades a extração de mel, geleia real, geoprópolis e ainda a polinização de espécies vegetais, entre outras vantagens, como a alimentar (WITTER e NUNES-SILVA, 2014). A produção de mel destas abelhas é inferior à das abelhas da espécie Apis mellifera, ou abelhas africanizadas, amplamente conhecidas por sua alta produção de mel. Porém, apesar dessa desvantagem, as abelhas-sem-ferrão são muito mais adaptadas ao nosso país, clima e vegetação (CAMARGO, OLIVEIRA e BERTO, 2017).

A meliponicultura pode se constituir em importante fonte de renda para o agricultor familiar por requerer um baixo investimento inicial e necessitar de pouco espaço na propriedade, podendo inclusive ser uma atividade paralela a outras já executadas nas pequenas propriedades rurais. Órgãos públicos de extensão rural têm incentivado essa prática e apoiado os agricultores nela interessados.

Ademais, nos últimos anos, novas normas regulamentares têm surgido para facilitar a regularização de pequenos empreendimentos rurais produtores de alimentos, favorecendo a maior comercialização e a inclusão social. Ao lado de normas federais, como a RDC 49, de 2013, da Agência Nacional de Vigilância Sanitária (ANVISA) (BRASIL, 2013), que dispõe sobre a regularização de atividades de interesse sanitário do microempreendedor individual, do empreendimento familiar rural e do empreendimento econômico solidário, estados como o Paraná também lançaram regulamentos próprios com essa finalidade, como a Resolução SESA 04, de 2017, que aprova o regulamento sobre as boas práticas de fabricação de alimentos processados pelo empreendimento familiar rural. Também no Paraná, um novo sistema de registro e inspeção, voltado exclusivamente aos alimentos de origem animal de pequenos produtores, foi regulamentado em 2020 , permitindo que após regularização do empreendimento no Serviço de Inspeção Municipal, os produtos sejam comercializados em todo o estado, desde que o órgão municipal de inspeção tenha aderido ao novo sistema (PARANÁ, 2020). 
Os méis de abelhas-sem-ferrão são produtos únicos da biodiversidade brasileira e possuem uma valorização expressiva no mercado regional e também nacional, em virtude de suas características peculiares, em termos de cor, aroma e sabor. Uma das principais características deste mel é o seu maior teor de umidade e acidez mais acentuada, quando comparado ao mel proveniente da espécie Apis mellifera (CHUTTONG et al., 2016; VILLAS-BÔAS, 2018). Em termos culinários e mesmo tecnológicos, o mel de abelhas-sem-ferrão não é considerado um bom agente de corpo, em virtude da ausência de polissacarídeos, mas é valorizado pela alta gastronomia e empregado como ingrediente, por ser um produto nativo ligado à sustentabilidade e possuir um sabor exótico (SPITERI et al., 2015; CHUTTONG et al., 2016).

0 interesse pela utilização de mel de abelhas-sem-ferrão como substituto de outros adoçantes, em chás, bebidas, cereais e principalmente como ingrediente em refeições caseiras tem aumentado nos últimos anos. Como exemplo, projetos governamentais liderados pelo Ministério da Agricultura, Pecuária e Abastecimento (MAPA) incentivam a ampliação do consumo de mel nas merendas escolares através do Programa Nacional de Alimentação Escolar (PNAE).

Para participação em feiras e outros eventos de comercialização da agricultura familiar, o meliponicultor é incentivado a oferecer, além do mel em si, produtos derivados, agregando renda e maior diversidade de itens.

Barras de cereais são consideradas alimentos práticos e saudáveis, aportando fibras, vitaminas e sais minerais, além de possibilitar formulações com ingredientes regionais e nutritivos. Basicamente, uma barra de cereais consiste numa mistura de castanhas, grãos, flocos de cereais e outros ingredientes similares que são aglutinados por um xarope e depois cortados em formato de barras. Barras industrializadas empregam xarope de glicose de milho para a função de aglutinação, em razão de seu baixo custo e sua alta viscosidade a frio, a qual ajuda a estabilizar o formato das barras (SOARES, 2005).

0 artigo aqui apresentado tem o objetivo de relatar o desenvolvimento de uma barra de cereais com a substituição total do xarope de glicose comercial por mel de abelhas-sem-ferrão, ajustando-se as proporções de cada ingrediente e a temperatura de cozimento da calda para obtenção de um produto final estável e sensorialmente aceitável. Relata-se também a transferência desta técnica aos meliponicultores da região de Londrina-PR, como alternativa de diversificação e agregação de renda. A proposta é mostrar como ações simples, como essa interação entre universidade, instituição pública de extensão rural e a comunidade, podem contribuir para promover o empreendedorismo na agricultura familiar e consequentemente melhorar a qualidade de vida das pessoas.

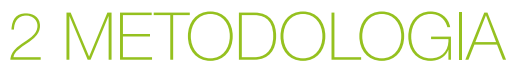

0 projeto de extensão teve a duração de um ano, considerando-se todas as atividades envolvidas: seleção de público-alvo, reunião das entidades participantes, desenvolvimento do produto, preparação e realização das capacitações com os produtores. Foi coordenado pelo Programa de Pós-Graduação em Ciência de Alimentos do Departamento de Ciência e Tecnologia de Alimentos (DCTA) do Centro de Ciências Agrárias (CCA) da Universidade Estadual de Londrina (UEL), com participação de associação de meliponicultores de Londrina e do Instituto de Desenvolvimento Rural do Paraná (IDR-IAPAR-EMATER), com divulgação feita pela TV UEL.

O público-alvo foram os meliponicultores da cidade de Londrina-PR e região metropolitana. Eles foram localizados por cadastros no IDR e convidados a participar do projeto por divulgação nas mídias sociais e pelo aplicativo WhatsApp, em grupos específicos.

A barra de cereais foi desenvolvida no Laboratório de Análise de Alimentos do DCTA. Os materiais utilizados foram: balança, assadeira, colher, espátula, faca, fogão, recipientes de vidro, termômetro e copo medidor. 0 mel usado foi proveniente da espécie Scraptotrigona bipunctata (popularmente conhecido como tubuna). A amostra de mel foi doada por meliponicultor que colabora com as pesquisas do grupo. Para sua caracterização, foram medidos o pH e o teor de sólidos solúveis. Para medição do pH, dois gramas de mel foram coletados em um béquer de $150 \mathrm{~mL}$, adicionando-se $50 \mathrm{~mL}$ de água e a solução foi misturada com agitador magnético por três minutos. Na sequência, realizou-se a medição em pHmetro de bancada PHOX P1000, conforme instruções do fabricante. A amostra apresentou um valor médio de $\mathrm{pH}$ de 4,19. Para análise da concentração de sólidos solúveis, uma alíquota de $3 \mathrm{~mL}$ de mel foi adicionada diretamente ao prisma do refratômetro de bancada Mettler Toledo RM40 e fez-se a leitura conforme instruções do fabricante. A amostra apresentou um valor médio de sólidos solúveis de $75^{\circ}$ Brix.

Para a elaboração da barra, os ingredientes sólidos foram selecionados considerando a disponibilidade, custo e saudabilidade. Houve preocupação em desenvolver um processo simples e acessível aos meliponicultores no campo. Inicialmente, todos os ingredientes foram separados para fácil manuseio (Fig. 1). 
Figura 1 - Foto de 14 de setembro de 2019 mostra os ingredientes utilizados na produção da barra de cereais com mel de abelha-sem-ferrão.

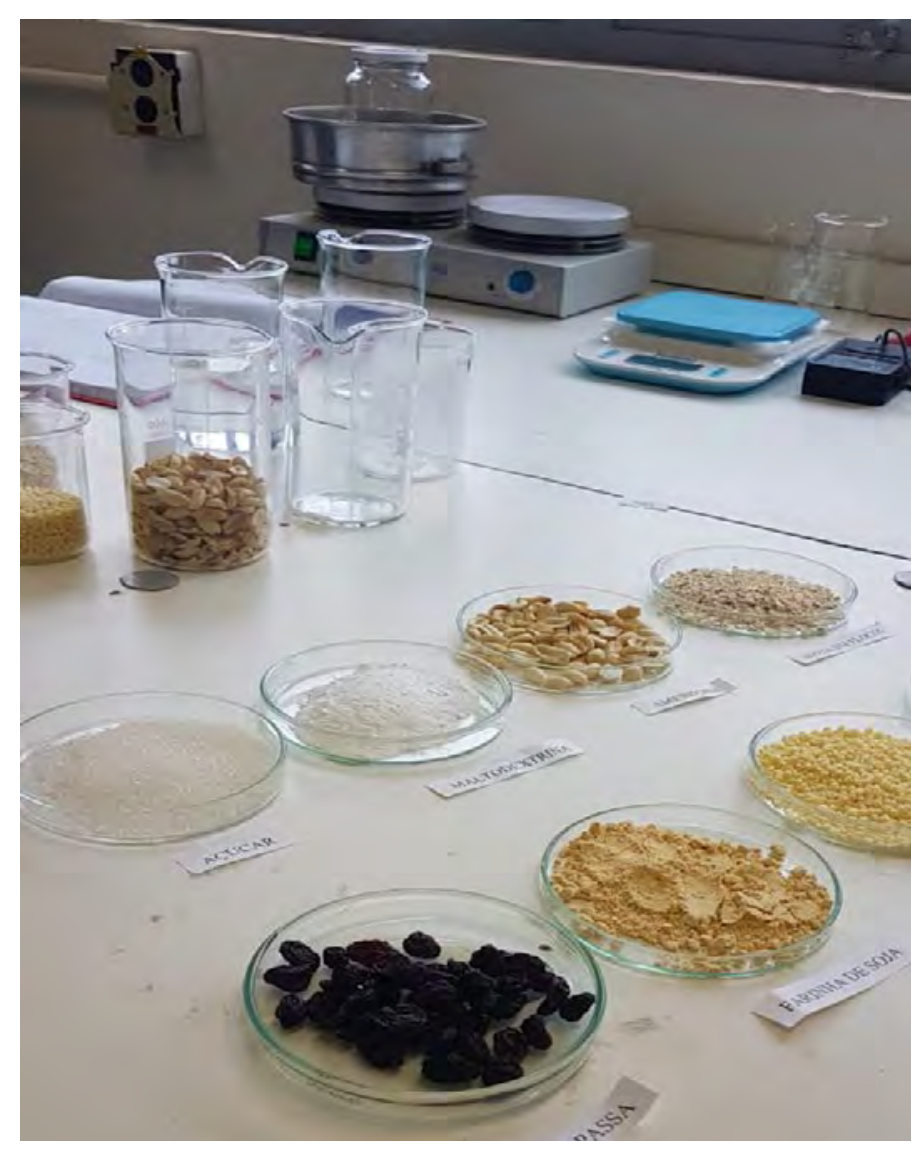

FONTE: Dados desta pesquisa.

Em um forno previamente aquecido a 180 으, colocou-se o amendoim em uma assadeira para torra, permanecendo até que a casca começasse a ficar escura. Depois de esfriar, as películas foram retiradas com as mãos.

Para a formulação, após vários testes foram definidas as porcentagens de $15 \%$ de mel de abelhasem-ferrão, $30 \%$ de calda cozida e $55 \%$ de um mix sólido. Foi elaborada uma calda com os seguintes ingredientes: $39 \mathrm{~g}$ de maltodextrina, $141 \mathrm{~g}$ de açúcar e $180 \mathrm{~mL}$ de água, os quais foram misturados e cozidos até a temperatura chegar a 135 으. Enquanto se concentrava a calda, foram pesados os ingredientes do mix sólido, conforme a Tabela 1.

Tabela 1 - Composição do mix sólido da barra de cereais desenvolvida

\begin{tabular}{lc}
\multicolumn{1}{c}{ INGREDIENTES } & CONCENTRAÇÃO (\%) \\
\hline Amendoim & 60,5 \\
\hline Uva-passa & 15,1 \\
\hline Flocos de arroz & 9,7 \\
\hline Aveia em flocos & 7,4 \\
\hline Farinha de soja & 6,1 \\
\hline Gérmen de trigo & 1,2 \\
\hline
\end{tabular}

FONTE: Os autores. 
Os ingredientes sólidos foram misturados e levados ao forno em assadeira, em baixa temperatura, para pequena elevação da temperatura, de modo a facilitar a posterior mistura com a calda. Quando a calda atingiu 135으, foi retirada do fogo e rapidamente foi misturada com o mel. Em seguida, derramou-se esta calda sobre o mix de castanhas e cereais na assadeira, mexendo-se rapidamente. A mistura foi distribuída uniformemente na assadeira e aguardou-se o resfriamento completo até temperatura ambiente, quando então se fez o corte em formatos retangulares e as barras foram embaladas. 0 desenvolvimento da barra (Fig. 2) foi realizado por uma estudante de graduação em Química e por uma estudante de pós-graduação em Ciência de Alimentos, sob orientação de uma docente do DCTA e de um extensionista do IDR-IAPAR-EMATER.

Figura 2 - Foto de 10 de junho de 2019 mostra um dos testes da barra de cereais com mel de abelhasem-ferrão desenvolvida no projeto.

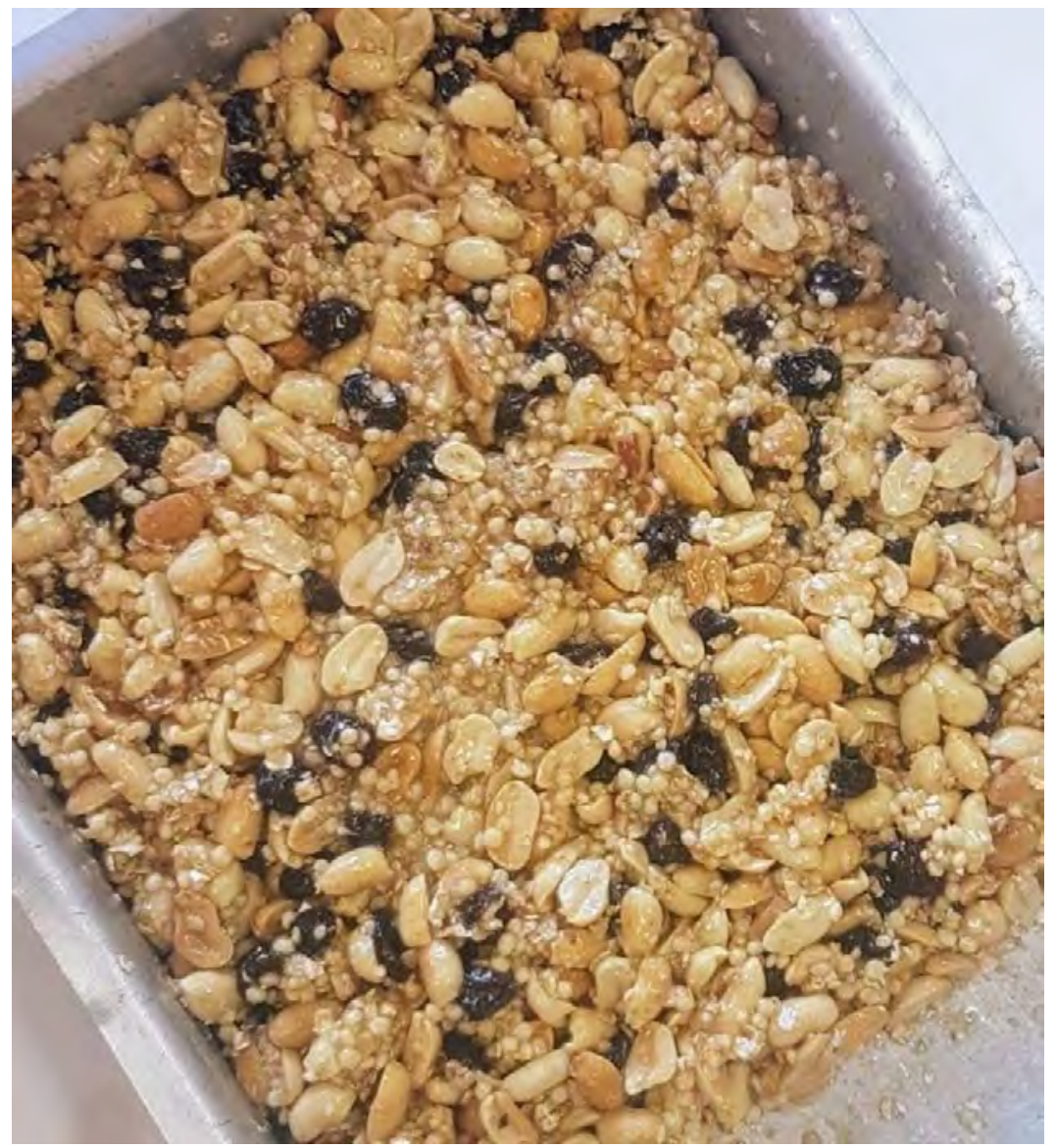

FONTE: Dados desta pesquisa.

No evento "Oficinas de Produtos Derivados de Mel de Abelhas-Sem-Ferrão", realizado na UEL, no segundo semestre de 2019, os meliponicultores receberam inicialmente capacitação em "Boas Práticas de Fabricação na extração de mel", com duração de 1 h30, ministrada por quatro discentes. Os temas abordados foram: métodos de colheita para a conservação do mel, métodos de manipulação e armazenamento e análises físico-químicas para controle de qualidade. Na sequência, foi ministrado um curso teórico sobre a barra de cereais e uma oficina prática com demonstração da elaboração da barra com mel de abelha-semferrão, com duração de 3 horas no total, apresentados em conjunto por uma discente e por um extensionista rural. No final do evento, as barras foram distribuídas para degustação.

As discentes foram responsáveis pelo preparo do material (levantamento bibliográfico sobre o tema, legislação, fotos e imagens) e pela apresentação, além da interação com os meliponicultores. Além dos professores e do extensionista rural, a organização do evento contou com o envolvimento de outros dois alunos da pós-graduação em Ciência de Alimentos e de colaboradores da Universidade Tecnológica Federal do Paraná, campus Londrina, os quais compuseram no total uma equipe de 11 pessoas. 


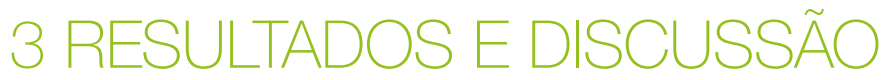

Observou-se a viabilidade da utilização de mel de abelhas-sem-ferrão na produção de barra de cereais, em proporção significativa (15\%), uma vez que o produto final apresentou textura, sabor e aparência adequados e similares ou superiores às barras de cereais comerciais. Para obtenção da formulação final, foram realizados cerca de dez experimentos, testando-se diferentes temperaturas de cozimento da calda e alterações nos tipos e nas proporções dos componentes sólidos e líquidos. Nas condições dos testes, empregando chama baixa para concentração do xarope, o tempo total usado para a elaboração do produto final foi de aproximadamente duas horas (cerca de $300 \mathrm{~g}$ ). Porém, com uma fonte de calor mais efetiva, 0 tempo pode ser significativamente reduzido, tendo-se em vista que o procedimento de maior duração é o cozimento da calda.

Outros autores já relataram uso de mel na composição de barras de cereais. Yadav e Bhatnagar (2015) constataram que, pelos atributos sensoriais, misturas de mel e xarope de milho funcionam como bons agentes aglutinantes para produção da barra de cereal. Diversos estudos também empregaram mel em barras de cereais, mas apenas como ingrediente adjunto, em pequenas quantidades, entre outros ingredientes funcionais (TORRES, 2009; NUNES et al., 2013; LANSING, 2017). Por sua vez, Leite et al. (2018) produziram uma barra de cereais usando mel de Apis melífera como agente aglutinante, em substituição total ao xarope de glicose de milho tradicional. Eles verificaram que a textura da barra de cereais com mel não atingiu o aspecto resistente esperado, impossibilitando o corte em formato retangular. Em nosso caso, atingimo uma consistência satisfatória ao encontrar uma proporção adequada entre mel (15\%), calda cozida (30\%) e componentes sólidos (55\%) e pelo aquecimento da calda até $135^{\circ} \mathrm{C}$ antes da adição do mel. A alta temperatura da calda justifica-se pela necessidade de concentrá-la para compensar o alto teor de umidade do mel de abelhas-sem-ferrão (em torno de 25\%).

A transferência dessa tecnologia de produção aos produtores rurais e de outros conhecimentos pertinentes à produção de mel aconteceu em evento com 45 participantes, entre meliponicultores, agricultores familiares, professores e alunos (Fig. 3). Com isso, os alunos se aproximaram dos produtores para conhecer na prática as técnicas de produção de mel, e consequentemente, houve junção de conhecimento técnico e experiência extensionista voltada ao atendimento do agricultor familiar (Fig. 4). Após o evento, os alunos relataram melhoria na autoestima e satisfação pela aplicabilidade de seus estudos teóricos em atividade prática, com transferência de conhecimento e interação com os participantes, considerando que houve aprendizagem mútua.

Figura 3 - Foto de 14 de setembro de 2019 mostra a coordenadora da pesquisa na abertura do "Curso sobre Boas Práticas de Fabricação na produção de mel" ofertado aos meliponicultores na Universidade Estadual de Londrina.

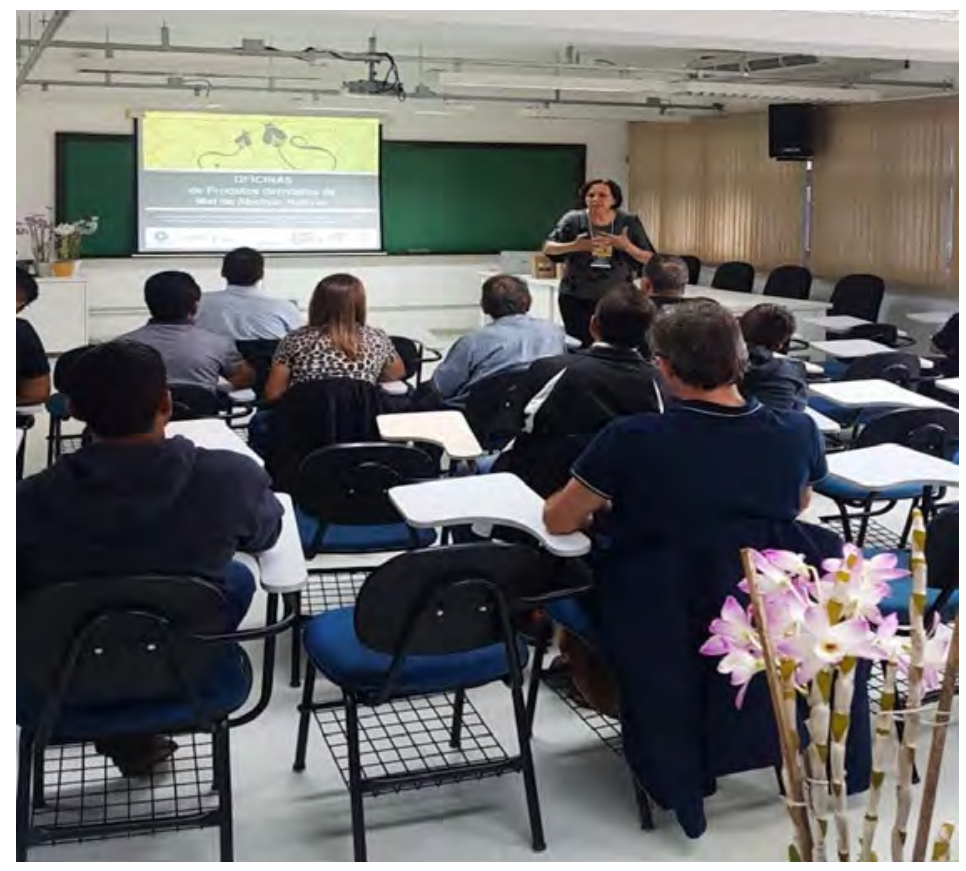

FONTE: Dados desta pesquisa. 
Figura 4 - Foto de 14 de setembro de 2019 mostra a oficina "Produção de barra de cereais com mel de abelha-sem-ferrão" ofertada aos meliponicultores na Universidade Estadual de Londrina.

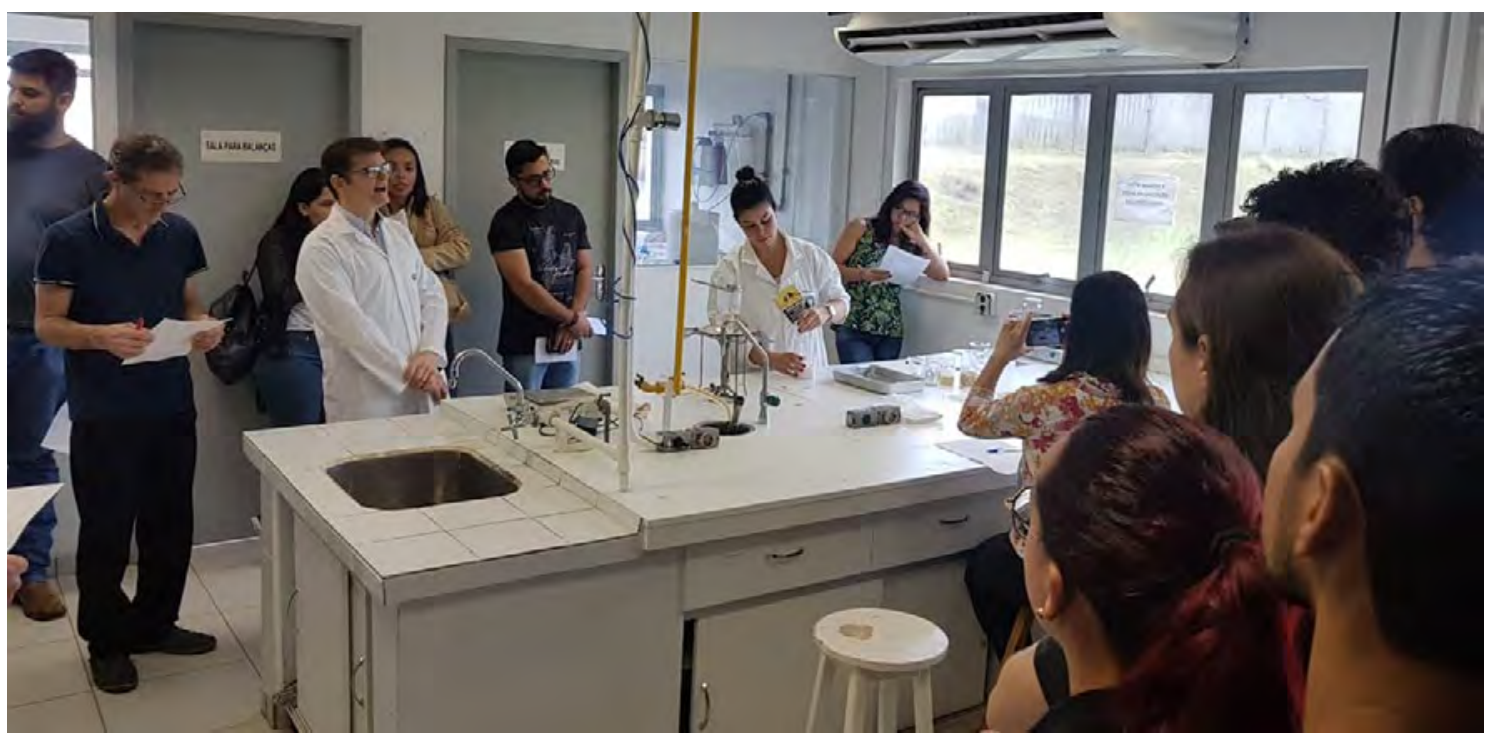

FONTE: Dados desta pesquisa.

É importante destacar que a fabricação da barra de cereais não constitui um processo complexo e não exige investimento em equipamentos. Dessa forma, o produto despertou o interesse dos meliponicultores, estimando-se que alguns já tenham iniciado sua produção (Fig. 5). Os agricultores familiares participaram, portanto, de um processo capaz de promover e apoiar estratégias que levem à sustentabilidade socioeconômica e ambiental, por meio da meliponicultura.

0 IDR-IAPAR-Emater continua acompanhando os produtores rurais de mel. Dois participantes deste projeto registraram aumento de produção e foram premiados em concurso estadual de méis em 2020. Posteriormente, em 2021, estes mesmos produtores solicitaram a alteração da instância de inspeção de seu estabelecimento de municipal para estadual, com a expectativa de ampliar sua área de comercialização. Os processos estão em tramitação. 0 Instituto ainda observou um aumento nas solicitações de apoio para regularização das instalações de produção de mel.

Figura 5 - Foto de 14 de setembro de 2019 mostra as barras de cereais com mel de abelha-sem-ferrão ofertadas para degustação aos meliponicultores na Universidade Estadual de Londrina.

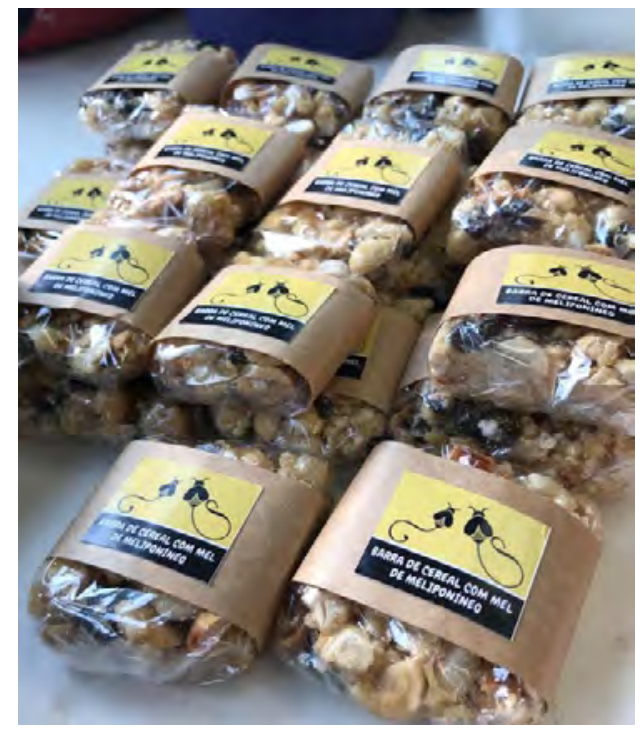

FONTE: Dados desta pesquisa. 


\section{CONSIDERAÇÕES FINAIS}

A execução do projeto resultou em um novo produto à base de mel de abelha-sem-ferrão, de fácil execução caseira e que, posteriormente, foi transferido a um grupo de meliponicultores. Estes, por sua vez, foram capacitados e incentivados a criar produtos similares, como uma alternativa de agregação de valor, diversificação da produção e desenvolvimento da economia, cultura e valores da comunidade.

Como resultado, os professores e alunos foram beneficiados por atenderem demandas reais da comunidade e pela interação com os produtores, além de trabalharem sobre temas de produção e tecnologia de alimentos relacionados à inclusão social. Os produtores tiveram acesso a conceitos científicos e a uma nova forma de geração de renda com o produto desenvolvido, além de suporte para a construção de um arranjo produtivo de mel de abelhas-sem-ferrão no qual coexistam integração social, ambiental e tecnológica.

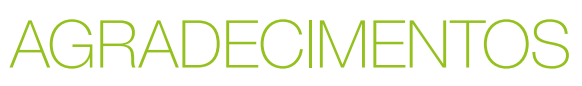

Ao Conselho Nacional de Desenvolvimento Científico e Tecnológico (CNPq), número do projeto: 431206/2016-3, 313769/2017-6 e ao FUNDO PARANÁ, Programa de Extensão "Universidade Sem Fronteiras", TC N. 112/18, da Superintendência Geral de Ciência, Tecnologia e Ensino Superior (SETI), pelo fomento e concessão de bolsas de estudo. Agradecemos também ao engenheiro agrônomo M.e Marcos Aparecido Gonçalves, da Superintendência Federal de Agricultura, Pecuária e Abastecimento no Estado do Paraná (SFA-PR), pelo apoio intelectual e aos meliponicultores Célia Regina Alberti Dresch e Antônio Carlos Stutz, que contribuíram com as amostras de mel para que as ações fossem desenvolvidas com êxito. Às discentes de graduação e pós-graduação que participaram das atividades: Viviane Lopes Leite da Costa, Milena Dias Poças, Taís Adeil Müller e Rebeca Priscila Flora Catarino. Aos docentes Lyssa Setsuko Sakanaka e Claudio Takeo Ueno pelo apoio no projeto.

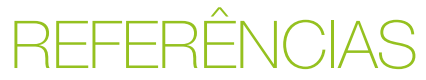

ANDRADE, Angela Leão et al. Trabalho de extensão como uma forma de geração de renda. Caminho Aberto: Revista de Extensão do IFSC, Florianópolis, v. 3, n. 5, 2016.

BRASIL. Agência Nacional de Vigilância Sanitária. RDC no 49, de 31 de outubro de 2013. Dispõe sobre a regularização de atividade de interesse sanitário do microempreendedor individual, do empreendimento familiar rural e do empreendimento econômico solidário. Disponível em: <https://bvsms. saude.gov.br/bvs/ saudelegis/anvisa/2013/rdc0049 3110 2013.html>. Acesso em: 19 abr. 2020

CAMARGO, Ricardo Costa Rodrigues; OLIVEIRA, Karen Linelle; BERTO, Maria Isabel. Mel de abelhas sem ferrão: proposta de regulamentação. Brazilian Journal of Food Technology, Campinas, v. 20, p. 1-6, 2017. DOI: doi. org/10.1590/1981-6723.15716

CARRETA, Regina Yoneko Dakuzaku; LOBATO, Beatriz Cardoso. A experiência de um projeto de extensão multidisciplinar no fomento à geração de renda cooperativa e solidária: a contribuição da Terapia Ocupacional. Revista de Cultura e Extensão USP, São Paulo, v. 4, p. 89-97, 2010. DOl: doi.org/10.11606/issn.2316-9060. v4iOp89-97

CHUTTONG, Bajaree et al. Physicochemical profiles of stingless bee (Apidae: Meliponini) honey from South East Asia (Thailand). Food Chemistry, Amsterdam, v. 192, p. 149-155, 2016. D0I: doi.org/10.1016/j. foodchem.2015.06.089

LANSING, Tamires. Elaboração, aceitabilidade e valor nutricional de barras de cereais produzidas a partir de farelo de torrone. 2017. 66f. Trabalho de Conclusão de Curso (Engenharia de Alimentos) - Universidade do Vale do Taquari, Lajeado, 2017.

LEITE, Mariana Aparecida et al. Barrinha de cereal com uso de mel em substituição do xarope de aglutinação. Anais do Congresso Nacional Universidade, EAD e Software Livre, Alfenas, v. 2, n. 9, 2018. Disponível em: $<$ www.periodicos.letras.ufmg.br/index.php/ueadsl/article/view/14411>. Acesso em 19 abr.2020 
LIMA, Antônia Francisca; SILVA, Edvânia Gomes de Assis; IWATA, Bruna de Freitas. Agriculturas e agricultura familiar no Brasil: uma revisão de literatura. Revista Retratos de Assentamentos, Araraquara, v. 22, n. 1, p. 5068, 2019. DOI: doi.org/10.25059/2527-2594/retratosdeassentamentos/2019.v22i1.332

MELO, Hanah Maria Torres. Gerando renda e inclusão social através do artesanato da fibra da bananeira.

Participação, Brasília, v. 27, 2015.

NUNES, Jarderlany Souza et al. Produção, análise sensorial e físico-química de barra de cereal produzidas com derivados de caju. Revista Verde de Agroecologia e Desenvolvimento Sustentável, Mossoró, v. 8, n. 2, p. 178-182, 2013.

PARANÁ. Secretaria da Agricultura e Abastecimento. Portaria ADAPAR no 081, de 29 de abril de 2020. Estabelece requisitos para adesão de Municípios ou Consórcio de Municípios ao Sistema Unificado de Atenção à Sanidade Agropecuária, com atenção especial à Agricultura Familiar e de Pequeno Porte no Paraná - Disponível em: <www.adapar.pr.gov.br/sites/adapar/arquivos restritos/files/migrados/File/ATG/AIC/Imagens/ anex0234182 539341.pdf> Acesso em: 19 abr. 2020

SOARES, José Humberto. Efeitos do xarope com alto teor de maltose em balas duras depositadas. 2005. 84f. Dissertação (Mestrado) - Programa de Pós-Graduação em Ciência de Alimentos, Centro de Ciências Agrárias, Universidade Estadual de Londrina, Londrina, 2005.

SPITERI, Marc et al. Fast and global authenticity screening of honey using $1 \mathrm{H}-\mathrm{NMR}$ profiling. Food Chemistry, Amsterdam, v. 189, p. 60-66, 2015. D0I: doi.org/10.1016/j.foodchem.2014.11.099

TORRES, Edmilson Rebelo. Desenvolvimento de barras de cereais formuladas com ingredientes regionais. 2009. 78f. Dissertação (Mestrado em Engenharia de Processos), Universidade Tiradentes, Aracaju, 2009.

VILLAS-BÔAS, Jerônimo. Manual tecnológico de aproveitamento integral dos produtos das abelhas nativas sem ferrão. 2. ed. Brasília: Instituto Sociedade, População e Natureza (ISPN), 2018.

WITTER, Sidia; NUNES-SILVA, Patrícia. Manual de boas práticas para o manejo e conservação de abelhas nativas (meliponíneos). Porto Alegre: Fundação Zoobotânica do Rio Grande do Sul, 2014.

YADAV, Latika; BHATNAGAR, Vibha. Optimization of ingredients in cereal bar. Food Science Research Journal, Muzaffarnagar, v. 6, n 2, p. 273-278, 2015. 